\title{
QUANTIFICAÇÃO DE PROPÁGULOS DE Gibberella zeae NO AR E INFECÇÃO DE ANTERAS EM TRIGO*
}

\author{
EDIVAN PANISSON**, ERLEI M. REIS \& WALTER BOLLER
}

\author{
Faculdade de Agronomia e Medicina Veterinária, Universidade de Passo Fundo, CEP 99001-970, \\ Cx. Postal 601, Passo Fundo, RS, e-mail: erleireis@uol.com.br
}

(Aceito para publicação em 11/06/2002)

\section{Autor para correspondência: Erlei Melo Reis}

PANISSON, E., REIS, E.M. \& BOLLER, W. Quantificação de propágulos de Gibberella zeae no ar e infecção de anteras em trigo. Fitopatologia Brasileira 27:489-494. 2002.

\section{RESUMO}

Devido ao aumento da ocorrência e da intensidade de epidemias nos últimos anos, a giberela tem sido apontada como uma das doenças que mais danos causa em cereais de inverno. $\mathrm{O}$ principal inóculo do fungo patógeno (Giberella zeae) são os ascosporos produzidos em peritécios sobre os restos culturais da maioria das espécies cultivadas. Os esporos são transportados a longas distâncias pelo vento e depositados sobre as anteras causando infecção. Os objetivos do presente trabalho foram quantificar a densidade de esporos no ar, a incidência da infecção em anteras de trigo (Triticum aestivum), a intensidade da doença no campo e elucidar o papel das anteras no processo infeccioso.
Durante o período correspondente à antese do trigo, foram coletados, em média, 6,6 esporos/10 $\mathrm{cm}^{2} / \mathrm{dia}$, em 1999 e 13,5 esporos $/ 10 \mathrm{~cm}^{2} /$ dia em 2000 . No estádio de floração plena, a infecção por G. zeae foi de $11,8 \%$ nas anteras soltas e de $24,3 \%$ nas anteras presas. As condições ambientais após a antese influenciaram a intensidade da doença no campo. Os resultados reforçam que as anteras presas desempenham um papel importante no processo infeccioso e, portanto, devem ser os principais sítios de infecção a serem protegidos com fungicidas.

Palavras-chave adicionais: giberela, densidade de inóculo, Fusarium graminearum.

\section{ABSTRACT \\ Assessment of air-borne inoculum of Gibberella zeae and the infection of anthers in wheat crops}

Because of its increasing frequency and intensity, head blight has been one of the most important diseases of winter cereal crops. Head blight causes both qualitative and quantitative losses. The ascospores formed on plant debris of many cultivated species are disseminated by the wind over long distances and can infect plant spikes through the anthers. The objectives of this research work were to quantify the air-borne inoculum of Gibberella zeae, the inoculum on the anthers, the disease intensity in the field, and the role of anthers in the infection process. The number of ascospores collected during wheat (Triticum aestivum) anthesis ranged from $6.6 / \mathrm{cm}^{2}$.day in 1999 to $13.5 / \mathrm{cm}^{2}$.day in 2000 . At complete flowering, the infection by G. zeae reached $11.8 \%$ on loose anthers and $24.3 \%$ on those trapped. The environmental conditions that followed anthesis influenced disease development in the field. The trapped anthers played an important role in the disease epidemiology, and should be sprayed with fungicide to prevent spike infection after anthesis.

\section{INTRODUÇÃO}

A giberela é uma doença que ocorre em órgãos florais de todos os cereais de inverno. O principal agente causal é o fungo Gibberella zeae (Schw.) Petch. cuja forma assexuada é Fusarium graminearum (Schwabe). A partir da década de 90, epidemias com maior freqüência e intensidade têm sido observadas em todas as regiões do mundo (Mauler-Machnik \& Zahn, 1994; McMullen et al., 1997). A manutenção dos restos culturais sobre o solo, a rotação de culturas com hospedeiros suscetíveis, a falta de cultivares resistentes e a baixa eficiência do controle químico têm sido apontados como os principais fatores relacionados com o aumento da intensidade da doença (Mauler-Machnik \& Zahn, 1994).

\footnotetext{
* Parte da Dissertação de Mestrado do primeiro autor. Universidade de Passo Fundo (2001)

** Bolsista da CAPES.
}

A giberela pode ser uma doença devastadora quando a floração (antese) dos cereais ocorre em épocas onde as temperaturas são superiores a $20{ }^{\circ} \mathrm{C}$ e a duração do molhamento das espigas é maior que $72 \mathrm{~h}$ (McMullen et al., 1997). Os danos causados são quantitativos, com a redução do rendimento (Reis, 1988a; Bai \& Shaner, 1994; MaulerMachnik \& Zahn, 1994; Parry et al., 1995) e qualitativos pela diminuição do peso hectolítrico, do teor de proteínas, do poder germinativo, do vigor das sementes e principalmente pela presença de micotoxinas nos grãos (Reis, 1988a; Tuite et al., 1990; Bai \& Shaner, 1994; Mauler-Machnik \& Zahn, 1994; Mesterházy \& Bartók, 1996).

Sobre os restos culturais da maioria das gramíneas nativas e de plantas daninhas são formandos os peritécios do fungo principalmente sobre os nós. Os resíduos são considerados a principal fonte de inóculo de G. zeae (Sutton, 1982; Reis, 1988a; Khonga \& Sutton, 1988; Bai \& Shaner, 1994). 
A liberação dos ascosporos dos peritécios é um processo ativo (Tschanz et al., 1975) e é regulada pela hidratação dos ascocarpos (Sutton, 1982; Reis, 1990; Suty \& MaulerMachnik, 1996). A liberação dos ascosporos ocorre durante todo o ano, pois os corpos de frutificação são detectados sobre os restos culturais durante o mesmo período (Reis, 1988b). Os ascosporos são liberados em maior quantidade durante a noite em relação ao dia (Reis, 1988b; Paulitz, 1996) possivelmente por estar relacionado com a sua embebição pela presença mais frequente da água à noite.

A dependência das anteras no processo infeccioso foi esclarecido somente na década de 70. Demonstrou-se que as anteras são os sítios de infecção do patógeno e que a colina e a betaina presentes nestes órgãos promovem o crescimento rápido do fungo para a invasão posterior dos tecidos da espiga (Strange \& Smith, 1971; Strange et al., 1974).

Em 1920, Atanasoff (1920) observou que após a antese o trigo (Triticum aestivum L.) ainda apresentava suscetibilidade à infecção por G. zeae. Pugh et al. (1933) também relataram que as anteras presas entre as glumas serviam de sítio de infecção para o fungo após a antese e que sua presença poderia contribuir para esclarece o por que da infecção prolongar-se desde o início da antese até a maturação fisiológica das cariopses. Takegami (1957) demonstrou haver uma relação entre a presença das anteras presas e a infecção inicial das espigas. Mais recentemente, Reis et al. (1996) também comprovaram que a infecção ocorre principalmente pelas anteras presas, sendo menor nas soltas. A exposição das anteras soltas é efêmera, em geral se expõe de dia e no máximo em 24 h ocorre a deiscência. Para que a infecção ocorra é necessário que neste espaço de tempo que o patógeno atinja o interior da flor (Paulitz et al., 1996). O fungo, após ter infetado uma espigueta, cresce através do ráquis atingindo as espiguetas adjacentes, podendo colonizar toda a espiga (Reis, 1989; Bai \& Shaner, 1994).

No Sul do Brasil, a área sob o sistema plantio direto aumentou e, em conseqüência, o mesmo ocorreu com a quantidade de restos culturais mantidos sobre a superfície do solo. O agente causal, por ser um patógeno que possui habilidade de competição saprofítica, formando peritécios em diferentes substratos senescidos, provavelmente tenha aumentado inóculo em relação à época anterior ao uso generalizado do plantio direto.

A hipótese formulada neste trabalho foi de que as epidemias ocorrentes nesta região, na última década, podem ser atribuídas a uma maior disponibilidade de inóculo no ar.

Os objetivos deste trabalho foram quantificar a densidade de esporos de G. zeae no ar, a infecção em anteras de trigo, a intensidade da doença no campo e quantificar a importância relativa das anteras soltas e presas no processo infeccioso.

\section{MATERIAL E MÉTODOS}

\section{Quantificação de propágulos de Gibberella zeae e de Fusarium graminearum no ar, em 1999}

As avaliações foram feitas em áreas cultivadas com trigo na Área Experimental da Faculdade da Agronomia e Medicina Veterinária da Universidade de Passo Fundo, implantados em sistema plantio direto sobre restos culturais de soja [Glicyne max (L.) Merrill], durante o período de 16 de setembro até 11 de novembro de 1999. Neste período, foram monitoradas as condições ambientais, determinando-se a temperatura e a umidade relativa do ar com um termohigrógrafo (THG-1/Hidrologia). As espigas foram consideradas molhadas quando a umidade relativa foi $\geq 80 \%$. Os dados de precipitação pluvial foram obtidos da estação meteorológica da Embrapa-Trigo, localizada a aproximadamente $1 \mathrm{~km}$ do local do experimento (Cunha, 2001).

Para a coleta e quantificação dos ascosporos de G. zeae e dos macroconídios de $F$. graminearum no ar, utilizaram-se quatro coletores de esporos tipo cata-vento, descritos por Reis $\&$ Santos (1985), posicionados na altura das espigas. A superfície de impacto dos esporos foi uma lâmina de microscópio (7,5 x 2,5 cm) untada com uma solução de vaselina descrita por Frederickson et al. (1987). As lâminas permaneceram expostas ao impacto dos esporos por um período de cinco dias sendo substituídas periodicamente neste mesmo intervalo. Em laboratório, na região central da lâmina, adicionou-se uma gota de lactofenol e uma lamínula de 3,2 x 2,4 cm. A identificação e quantificação dos ascosporos de G. zeae foi feita em quatro lâminas por amostra, em uma área de 7,68 cm², com auxilio de um microscópio óptico com objetiva de 40x.

\section{Quantificação de propágulos de Gibberella zeae e de Fusarium graminearum no ar, em 2000}

No ano de 2000, os quatro coletores de esporos foram instalados em plantios de trigo em área experimental no Centro de Extensão e Pesquisa Agronômica da Faculdade da Agronomia e Medicina Veterinária da Universidade de Passo Fundo, implantados em sistema plantio direto sobre restos culturais de milho (Zea mays L.). A quantificação foi realizada de 21 de setembro a 19 de outubro de 2000. Neste período, foi monitorada a temperatura do ar, a umidade relativa do ar, a duração do molhamento foliar e a precipitação pluvial com uma mini-estação meteorológica (Watch-Dog model 450).

Utilizaram-se os mesmos coletores de esporos do experimento anterior, instalados da mesma forma. Porém, ao invés de utilizarem-se lâminas de microscopia como superfície de impacto na coleta dos propágulos, utilizaram-se placas de Petri de $6,5 \mathrm{~cm}$ de diâmetro de modo a obter uma maior superfície coletora dos esporos $\left(33,2 \mathrm{~cm}^{2}\right)$. Em cada placa foram vertidos $20 \mathrm{ml}$ de meio de cultura seletivo à Fusarium (Nash \& Snyder, 1962). Diariamente trocavam-se as placas e no laboratório foram mantidas em câmara climatizada a $25 \pm 2$ ${ }^{\circ} \mathrm{C}$ com fotoperíodo de $12 \mathrm{~h}$. Após $72 \mathrm{~h}$, com o auxílio de microscópio estereoscópico, efetuou-se a identificação e a contagem do número de colônias de $F$. graminearum.

\section{Infecção de anteras de espigas de trigo por Gibberella zeae}

Em seis experimentos de controle químico de $G$. zeae em trigo, foram coletadas no estádio 65 da escala fenológica de Zadoks et al. (1974) aproximadamente 20 espigas para 
determinar a infecção das anteras pelo patógeno. No laboratório dissecaram-se assepticamente as espiguetas, removeramse as anteras soltas e presas das espigas plaqueando-as em meio seletivo (Nash \& Snyder, 1962). Como antera solta considerouse aquela que permaneceu exposta externamente, pendente pelo filete e presa aquela que permaneceu aprisionada entre as extremidades apicais das glumas, somente com o ápice visível. Após sete dias de incubação, em câmara climatizada à temperatura de $25 \pm 2{ }^{\circ} \mathrm{C}$, iluminada com lâmpadas fluorescentes luz do dia, distantes $35 \mathrm{~cm}$ das placas e fotoperíodo de $12 \mathrm{~h}$, foi determinado o número de colônias formadas a partir das anteras. Paralelamente, no campo, determinou-se a incidência da giberela em espigas de trigo em uma área de $0,8 \mathrm{~m}^{2}$ e $0,68 \mathrm{~m}^{2}$ para os anos de 1999 e 2000, respectivamente. A severidade obtida pelo produto da incidência pela porcentagem de espiguetas gibereladas dividido por 100 , foi determinada em 25 espigas coletadas de afilhos principais das plantas de trigo. As avaliações foram realizadas no estádio 85 da escala fenológica de Zadoks et al. (1974), em quatro repetições.

\section{RESULTADOS E DISCUSSÃO}

\section{Quantificação de propágulos de Gibberella zeae e de Fusarium graminearum no ar, em 1999}

O clima com precipitação pluvial abaixo da normal (Cunha, 2001) que ocorreu na safra de 1999 deve ter sido responsável pela baixa intensidade da doença no Rio Grande do Sul, porém em algumas lavouras onde o estádio de florescimento até a maturação coincidiu com períodos prolongados de molhamento devido a chuvas, registrou-se a ocorrência da doença.

A quantidade de esporos coletados - 6,6 esporos/10 $\mathrm{cm}^{2} /$ dia (macroconídios e ascosporos) foi 4,5 vezes superior às obtidas por Reis (1988b), que coletou 1,5 esporos $/ 10 \mathrm{~cm}^{2} /$ dia nos meses de setembro, outubro e novembro de 1984. A proporção de propágulos coletados foi $90 \%$ de ascosporos e $10 \%$ de macroconídios, proporções diferentes das encontradas por Reis (1988b) que havia sido de $98 \%$ e $2 \%$, respectivamente. A população de macroconídios foi maior provavelmente por dois motivos: a) proximidade dos coletores das espigas, onde nos dias chuvosos observou-se mais macroconídios; b) pela forma de avaliação que ocorria a cada cinco dias e como os ascosporos são muito pequenos podem ter sido subestimados. De qualquer forma, os ascosporos foram coletados em maior quantidade do que os macroconídios, confirmando as observações feitas por Sutton (1982), Khonga $\&$ Sutton (1988) e Reis (1998b).

Observa-se que mesmo em períodos sem chuva os ascosporos foram coletados no ar, e com a ocorrência de precipitação pluvial, a população aumentou, ratificando relatos de Sutton (1982), Reis (1988a), Reis (1990) e Suty \& Mauler-Machnik (1996) (Figura 1).

\section{Quantificação de propágulos de Gibberella zeae e de Fusarium graminearum no ar, em 2000}

Na safra tritícola de 2000, no Rio Grande do Sul, ocorreu provavelmente a maior epidemia de giberela, atingindo os cereais de inverno em todas regiões do estado.

Durante o período de amostragem, verificou-se em todos os dias a presença de propágulos no ar. Em 2000, a quantidade de esporos coletados $\left(13,5\right.$ esporos $\left./ 10 \mathrm{~cm}^{2} / \mathrm{dia}\right)$ foi o dobro da coletada em 1999 (6,6 esporos/10 cm²/dia). Logo após a ocorrência de chuvas, houve um aumento de propágulos coletados. Por outro lado, em períodos secos a quantidade de esporos foi menor. Nos dias 6, 7 e 8 de outubro, embora com chuva, observou-se uma redução do número de propágulos coletados, que pode ser atribuído à lavagem dos esporos na placa ou ao arraste dos esporos presentes no ar, pelas gotas da chuva.

A metodologia utilizada neste ano permitiu uma melhor observação da flutuação da densidade do inóculo no ar, já que as avaliações foram diárias. Em relação ao ano anterior, a quantidade de propágulos coletados foi o dobro, o que pode ser explicado por dois fatores: a) os coletores foram instalados sobre restos culturais de milho, principal substrato do patógeno (Sutton, 1982; Khonga \& Sutton, 1988); b) devido a ocorrência de chuvas durante todo o inverno, a produção de ascosporos pode ter sido maior, havendo liberação e produção freqüentes de inóculo.

A população de ascosporos presentes no ar é um indicador do potencial da doença no campo (Bai \& Shaner,1994; Francl, 1998) desde que existam condições favoráveis para a infecção, como ocorreu nesta safra.

O aumento na densidade de inóculo no ar deve estar relacionado com a manutenção dos restos culturais na superfície do solo devido ao sistema de plantio direto e com o aumento da área cultivada de milho no sul do Brasil. Desta forma as epidemias podem ser previstas somente com prognósticos de períodos prolongados de molhamento das espigas durante o estádio de suscetibilidade, já que a densidade de propágulos no ar é alta.

O aumento da pressão de inóculo é preocupante pois não se dispõem de métodos eficientes para controlar a doença. Bastam períodos chuvosos coincidirem com a antese para desencadear epidemias, causando danos às culturas, não só no Brasil, mas nas demais regiões onde se cultiva cereais de inverno.

Devido ao aumento da densidade de esporos no ar e ao uso de cultivares suscetíveis ou com resistência moderada, a doença deverá ocorrer sempre que durante o período da antese até ao estádio de grãos em massa dura ocorrerem períodos prolongados de chuva.

\section{Infecção de anteras de espigas de trigo por Gibberella zeae}

Confirmaram-se os resultados obtidos por Reis et al. (1996) de que a infecção das anteras presas é maior do que a ocorrida em anteras soltas. Pode-se concluir que, para os fungicidas controlarem a doença os mesmos devem ser aplicados de modo a atingir e cobrir as anteras, principalmente as presas, já que permanecerão expostas até o fim do ciclo da cultura. Na época 1, em 1999, observou-se que a infecção das anteras foi baixa (Tabela 1). Ao analisar as condições 


\section{E. Panisson et al.}

TABELA 1 - Quantidade de espigas amostradas e anteras de trigo (Triticum aestivum) plaqueadas em meio de cultura seletivo, porcentagem de infeção com Fusarium graminearum, incidência (I) e severidade (S) da doença. Passo Fundo, RS. 1999/2000

\begin{tabular}{|c|c|c|c|c|c|c|c|c|c|c|}
\hline \multirow[b]{2}{*}{ Época/ano } & \multirow[b]{2}{*}{ Floração* } & \multirow[b]{2}{*}{ Espigas ( $\left.\mathbf{n}^{0}\right)$} & \multicolumn{3}{|c|}{ Anteras plaqueadas $\left(\mathrm{n}^{0}\right)$} & \multicolumn{3}{|c|}{ Anteras infetadas (\%) } & \multirow[b]{2}{*}{ I (\%) } & \multirow[b]{2}{*}{$\mathrm{S}(\%)$} \\
\hline & & & Soltas & Presas & Total & Soltas & Presas & Total & & \\
\hline $1 / 1999$ & $26 / 09$ & 15 & 528 & 64 & 592 & 1,1 & 1,6 & 1,2 & 31,8 & 22,5 \\
\hline $2 / 1999$ & $08 / 10$ & 25 & 467 & 117 & 584 & 10,5 & 28,2 & 14,0 & 29,7 & 18,9 \\
\hline $3 / 1999$ & $18 / 10$ & 15 & 622 & 138 & 760 & 14,5 & 35,5 & 18,3 & 44,6 & 19,3 \\
\hline $1 / 2000$ & $03 / 10$ & 19 & 758 & 104 & 862 & 13,2 & 11,5 & 13,0 & 73,3 & 38,8 \\
\hline $2 / 2000$ & $10 / 10$ & 21 & 740 & 126 & 866 & 7,8 & 20,6 & 9,7 & 70,2 & 34,9 \\
\hline $3 / 2000$ & $17 / 10$ & 23 & 334 & 171 & 505 & 23,4 & 48,5 & 31,9 & 71,9 & 36,6 \\
\hline Total & - & 118 & 3449 & 720 & 4169 & - & - & - & - & - \\
\hline Média & - & 19,7 & 574,8 & 120,0 & 694,8 & 11,8 & 24,3 & 14,7 & 53,6 & 28,5 \\
\hline
\end{tabular}

* Data da floração plena segundo a escala fenológica de Zadoks, et al. (1974).
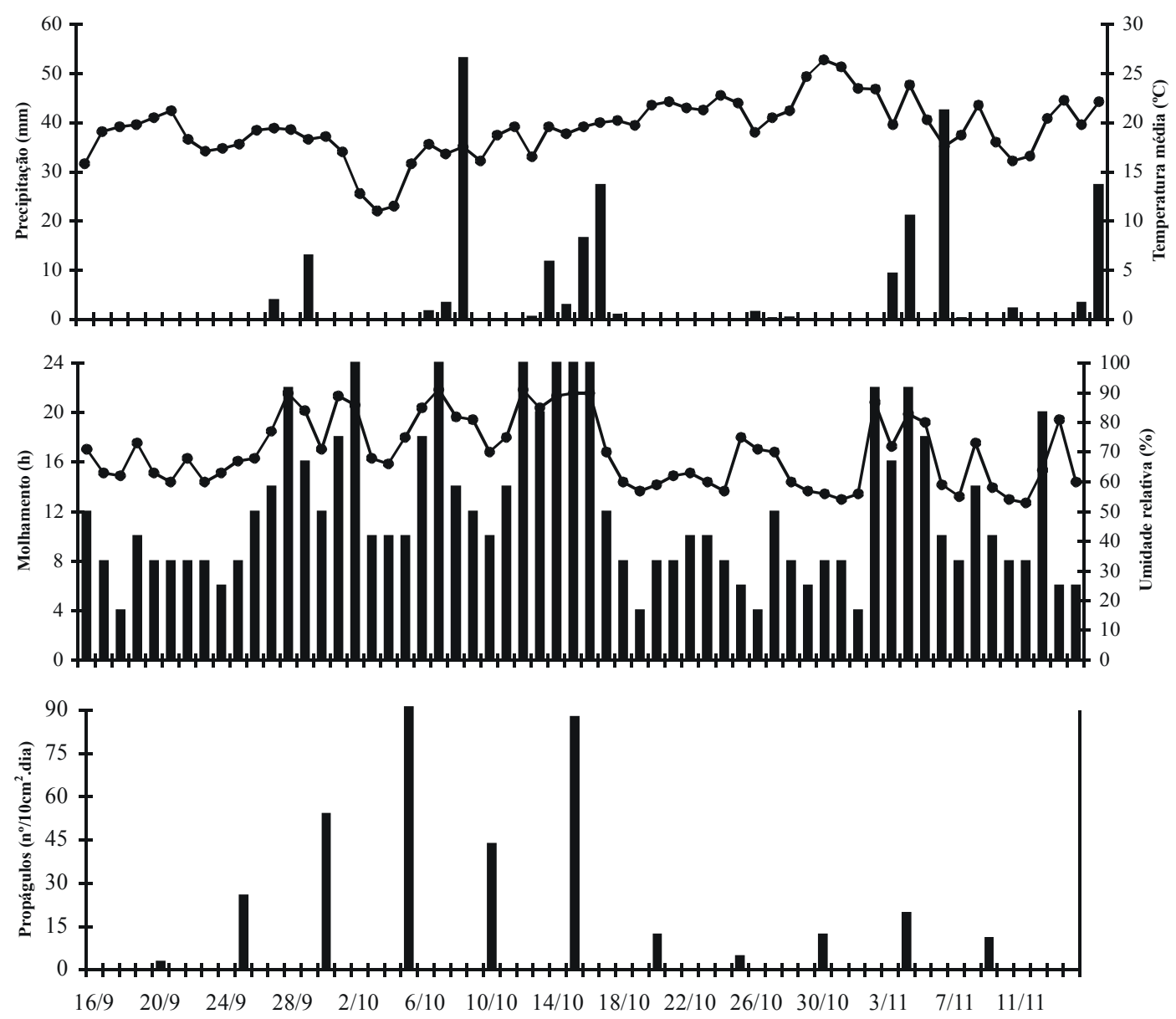

FIG. 1 - Condições ambientais e propágulos de Gibberella zeae/Fusarium graminearum coletados entre 16 de setembro e 11 de novembro. a) precipitação pluvial (colunas) e temperatura média do ar (linha); b) duração do molhamento foliar diário (colunas) e umidade relativa do ar média (linha); c) quantidade de propágulos. Passo Fundo, RS, 1999.

climáticas, verificou-se que foram desfavoráveis à infecção e que a densidade de inóculo no ar foi baixa, principalmente pela baixa frequência de chuvas (Figura 1). Com isso podese deduzir que a intensidade da doença também deveria ser baixa, porém, quando se observa a incidência e a severidade, verifica-se que foi semelhante às outras épocas de 1999 (Tabela 1). Esse raciocínio indica que as anteras presas podem ter aumentado o período de predisposição do hospedeiro, 
contribuindo para a infecção das espigas após a deiscência das anteras soltas.

Em 1999, nas épocas 2 e 3, ocorreram períodos com chuva durante a antese, o que aumentou o número de esporos coletados no ar (Figura 1). Em conseqüência, também houve um incremento de infecção nas anteras (Tabela 1). Em 2000, a alta quantidade de inóculo (Figura 2), refletiu-se diretamente na maior incidência do fungo nas anteras, sejam elas presas ou soltas. As condições de umidade e de temperatura elevadas podem ter favorecido a infecção refletindo em altas incidência
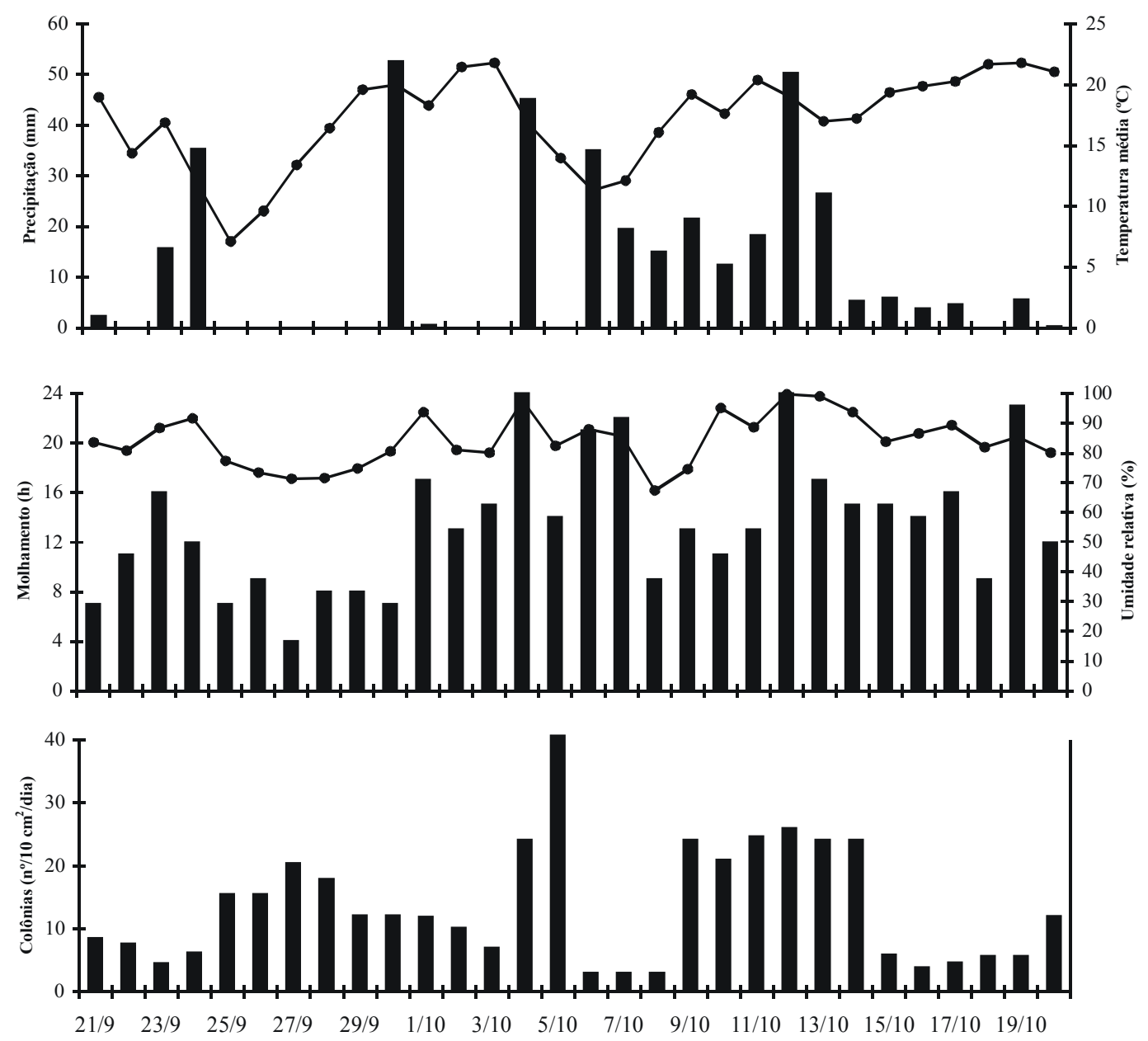

FIG. 2 - Condições ambientais e propágulos de Gibberella zeae/Fusarium graminearum coletados entre 21 de setembro e 19 de outubro. a) precipitação pluvial (colunas) e temperatura média do ar (linha); b) duração do molhamento foliar diário (colunas) e umidade relativa média do ar (linha); c) quantidade de propágulos. Passo Fundo, RS, 2000.

e severidade da doença (Figura 2).

A infecção das anteras não se relacionou com a intensidade da doença no campo, reforçando a hipótese de que a infecção pode ter ocorrido mais tarde através das anteras presas (Atanasoff, 1920; Pugh et al., 1933; Takegami, 1957; Reis et al., 1996).

Quando os fungicidas são aplicados e atingem as anteras, como acontece em casa de vegetação, eles apresentam controle satisfatório (Reis, et al., 1996). Ocorre que as anteras soltas têm duração efêmera ficando aproximadamente um dia expostas, período que o patógeno dispõe para invadir a espigueta (Paulitz et al., 1996). O desenvolvimento de cultivares que apresentem floração o mais uniforme possível, poderia contribuir para melhorar a eficiência do controle químico, já que maior número de anteras seriam atingidas pela calda. Atualmente, com as cultivares disponíveis, a duração da antese é longa, podendo durar até 19 dias (Vargas et al., 2000), e por isto, é difícil protegê-las durante toda a antese tendo em vista que mesmo os fungicidas com ação sistêmica atuam apenas como protetores, pois se supõe que nas anteras não exista xilema.

\section{AGRADECIMENTOS}

Agradecimentos são prestados à Bayer S.A. pelo suporte financeiro dado a execução deste trabalho. 


\section{REFERÊNCIAS BIBLIOGRÁFICAS}

ANDERSEN, A.L. The development of Gibberella zeae headblight of wheat. Phytopathology 38:595-611.1948.

ATANASOFF, D. Fusarium Blight (Scab) of wheat and other cereals. Journal Agricultural Research 20:1-32.1920.

BAI, G. \& SHANER, G. Scab of wheat: prospects for control. Plant Disease 78:760-766.1994.

CUNHA, G.R. Clima de Passo Fundo - Normais climatológicas. Capturado em 02 de janeiro de 2001. Online. http:// www.cnpt.embrapa.br

FRANCL L.J. Development of fusarium head blight in relation to environment and inoculum. In: Proceedings, The 1998 national fusarium head blight forum, Michigan, Unites States. 1998. pp. 1-4.

FREDERICKSON, D.E.; MANTLE, P.G. \& DE MELLIANO, W.A.J. Secondary condition of Sphacelia sorghi on sorghum, a novel factor in the epidemiology of ergot disease. Mycological Research 93: 497-502. 1987.

KHONGA, E.B. \& SUTTON, J.C. Inoculum production and survival of Gibberella zeae in maiz and wheat residues. Canadian Journal of Plant Pathology 10:232-239.1988.

MAULER-MACHNIK, A. \& ZAHN, K. Ear fusarioses in wheat new findings on their epidemiology and control with Folicur (tebuconazole). Pflanzenschutz-Nachrichten Bayer 47:129155.1994.

McMULLEN, M., JONES, R. \& GALLENBERG, D. Scab of wheat and barley: a re-emerging disease of devastating impact. Plant Disease 81:1340-1348.1997.

MESTERHAZY, A. \& BARTOK, T. Control of Fusarium head blight of wheat by fungicides and its effect on the toxin contamination of the grains. Pflanzenschutz-Nachrichten Bayer 49:181198.1996.

NASH, S.M. \& SNYDER, W.C. Quantitative estimations by plate counts of propagules of the bean root rot Fusarium in field soil. Phytopathology 52:567-572.1962.

PARRY, D.W., JENKINSON, P. \& McLEOD, L. Fusarium ear blight (scab) in small grain cereals - a review. Plant Pathology 44:207238.1995 .

PAULITZ, T.C. Diurnal release of ascospores by Gibberella zeae in inoculated wheat plots. Plant Disease 80:674-678.1996.

PUGH, G., JOHANN, W.H. \& DICKSON, J.G. Factors affecting infection of wheat heads by Gibberella saubinetii. Journal Agricultural Research 46:771-797.1933.

REIS, E.M. Doenças do trigo III; giberela. $2^{a}$ ed. São Paulo. 1988a.

REIS, E.M. Quantificação de propágulos de Gibberella zeae no ar através de armadilhas de esporos. Fitopatologia Brasileira 13:324-327.1988b.

REIS, E.M. Fusariosis: biologia y epidemiologia de Gibberella zeae en trigo. In: Kohli, M.M. (Ed.) Taller sobre la fusariosis de la espiga en America del Sur. México. Cimmyt. 1989. pp.97102.

REIS, E.M. Effects of rain and relative humidity on the release of ascospores and on the infection of wheat heads by Gibberella zeae. Fitopatologia Brasileira 15:339-343. 1990.

REIS, E.M \& SANTOS, H.P. População de Helmintosporium sativum no ar quantificado através de uma armadilha tipo cata-vento. Fitopatologia Brasileira 10:515-519. 1985.

REIS, E.M., BLUM, M.M.C. \& CASA, R.T. Controle químico de Gibberella zeae em trigo, um problema de deposição de fungicidas em anteras. Summa Phytopathologica 22:39-42. 1996.

STRANGE, R.N. \& SMITH, H. A fungal growth stimulant in anthers which predisposes wheat to attack by Fusarium graminearum. Physiological Plant Pathology 1:141-150. 1971.

STRANGE, R.N., MAJER, J.R. \& SMITH H. The isolation and identification of choline and betaine as the two major components in anthers and wheat germ that stimulate Fusarium graminearum in vitro. Physiological Plant Pathology 4:277290. 1974.

SUTTON, J.C. Epidemiology of wheat head blight and maize ear rot caused by Fusarium graminearum. Canadian Journal of Plant Pathology 4:195-209. 1982.

SUTY, A. \& MAULER-MACHNIK A. Fusarium head blight on wheat - new findings on the epidemiology and control of Gibberella zeae the teleomorph of Fusarium graminearum with Folicur. Pflanzenschutz-Nachrichten Bayer 49:55-70.1996.

TAKEGAMI, S. Studies on the resistance of wheat varieties to Gibberella zeae (Schw.) Petch. (head blight) and mecanism. 1. Varietal diferences of the position of florets in the wheat spikelet. Scientific Report of the Faculty of Agriculture 10:3342. 1957.

TSCHANZ, A.T., HORST, R.K. \& NELSON, P.E. Ecological aspects of ascospore discharge in Gibberella zeae. Phytopathology 65:597-599. 1975.

TUITE, J., SHANER, G. \& EVERSON R.J. Wheat scab in soft red winter wheat in Indiana in 1986 and its relation to some quality measurements. Plant Disease 74:959-962. 1990.

VARGAS, P.R., FERNANDES, J.M., PICININI, E.C. \& HUNT, A.L. Simulação de epidemia de giberela em trigo. Fitopatologia Brasileira 25:497-504. 2000.

ZADOKS, J.C., CHANG, T.T. \& KONZAC, C.F. A decimal code for the growth stages of cereals. Weed Research 14:415-421. 1974. 